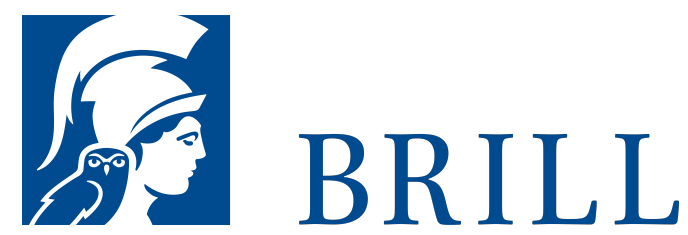

\title{
Mayas, Pochos und Chicanos
}

Die transnationale Nation

Author: Inge Baxmann

Die mexikanische Border-Culture, an der Grenze zwischen Mexiko und den USA entstanden, wurde seit den 198oer Jahren als Modell für postnationale Identität gefeiert. Gegen die äußere Bedrohung und die regionale und ethnische Zersplitterung des Landes, aber auch aus Furcht vor den Folgen der Migration setzten die postrevolutionären Regierungen auf die Entwicklung einer gemeinschaftsstiftenden volkstümlichen Nationalkultur. Mexikanische und internationale Künstler suchten in den prähispanischen Traditionen und in der Volkskunst nach einer mexikanischen Moderne, die in Film, Architektur und auf den „Fiestas Patrias“ inszeniert wurde. Um Europa den Rücken zu kehren, regionalisierte man moderne Strategien der Nationenbildung aus Europa. Die Geschichte der transnationalen Formationen in den postrevolutionären Inszenierungen der Nation und das Scheitern der BorderCulture zeigen die erstaunliche Flexibilität der Nationalkultur.

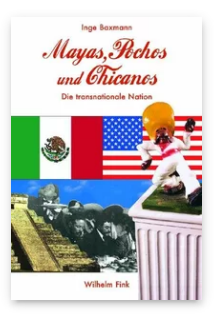

Pages: 172

Seiten, $20 \mathrm{~s} / \mathrm{w}$

Abb.

Language:

German

Subjects:

Cultural History,

Literature and

Cultural Studies

Publisher: Brill |

Fink

E-Book (PDF)

Released online:

29 Jan 2020

ISBN: $978-3^{-}$

8467-4340-9

List price

USD $\$ 42.00$

Paperback

Publication date:

12 Dec 2007

ISBN: $978-3-$

7705-4340-3

List price

USD $\$ 42.00$ 
For more information see brill.com

Order information: Order online at brill.com +44330 333 0049 | customerservices@brill.com Submission information: brill.com/authors

Titles published by Brill | Fink, Brill | mentis or Brill | Schöningh: +49(o)715413279216| brill@brocom.de 